\author{
https://doi.org/10.52449/1857-4114.2020.35-1.05 \\ CZU: 796.015:796.38
}

\title{
THE STUDY OF THE MOTIVATIONAL FACTORS OF PRACTICING FITNESS BY MEN IN THE REPUBLIC OF MOLDOVA
}

\author{
Craijdan Olga ${ }^{1}$ \\ Luca Aliona \\ ${ }^{1,2}$ State University of physical Education and Sport, Chisinau, Republic of Moldova
}

\begin{abstract}
This paper reflects the results of a study on the motivational factors of practicing fitness by men in the Republic of Moldova. Starting from the data from the specialized scientificmethodical literature, as well as from the results of their own observations, a sociological survey was developed (15 questions), which was applied to a group of 40 men who attend various fitness clubs in Chisinau. The study highlighted a number of aspects, the most important being the following: the profile of the subjects; general aspects of their fitness); the reasons that determine them to practice fitness, according to the three categories: related to physical condition, psychoemotional and cognitive sphere, socio-professional sphere, in order to determine the dominant motivational factors, those of increased importance and those of low importance; the degree of subjects satisfaction after practicing fitness; the role it assigns to fitness trainer/instructor in obtaining their results. The model for determining the motivational factors of practicing fitness by men can be proposed for application to coaches in fitness centers in our country, which would help maintain a constant interest of the population and, implicitly, to streamline the fitness training process.
\end{abstract}

Keywords: fitness, motivational factors, kinds of reasons, men, degree of reasons' manifestation.

The actuality of the research. Maintaining and strengthening the health of the population has been and continues to be one of the most important problems of human society. Today, the urge to be healthy, to adopt a healthy lifestyle comes from all sources: from the media of all levels, Internet, the scientific and didactic literature, which abounds in information on the usefulness and forms of practicing the physical exercise to ensure human health. However, the social environment and practical experience reflect a continuous worsening of it: it aggravates cardiovascular diseases, increases the frequency of other chronic diseases, increases the incidence and typology of infectious diseases, even about a "rejuvenation" of a number of diseases, traditionally considered "the prerogative" exclusively of the elderly ones. At the same time, the intense urbanization, the increase of the living standard of population, the technical-scientific progress, which, in the last decades, has known an accelerated development, the appearance of a series of new professions, and in the last months the exercise of a wide range of professional activities on online platforms, they directly led to a true chronic hypodynamia of the population. Thus, the actuality of this research is determined, on the one hand, by the need to maintain and strengthen the health of the active population of the country, as a strategic objective of contemporary society, and on the other hand by the growing number of different and occupational diseases, which appeared as a result of the influence of the professional activity conditions, geographical and climatic factors and even the way of people life. 
A study conducted in 2019 by "Magenta Consulting" reflects the fact that only $37 \%$ of Moldovans say they practice sport, only $17 \%$ attend gyms. Compared to the general population, this figure shows that only $6 \%$ of Moldovans go to gym. Globally, $27 \%$ of the adult population is member of a fitness center. Most of those who attend gyms in the Republic of Moldova are men (64\%), $85 \%$ are up to 50 years old and more than half are from Chisinau. The gyms are mostly visited by people with higher education $(69 \%$ of respondents), and 2/3 have a job, whether they are specialists and qualified workers, civil servants or hold a managerial position [7].

Thus, it is necessary to research the low level of interest of the adult population, including men, in the Republic of Moldova, compared to the practice of physical culture and sport and the development of strategies to stimulate it.

The purpose of the research: to determine the motivational factors of practicing fitness by men in the Republic of Moldova.

\section{Objectives of research:}

1. Analysis of current methodologicalscientific data on the importance of practicing fitness by men.

2. Elaboration and application of the sociological survey on the research topic.

3. Argumentation of the motivational factors of practicing fitness by men.

Methodology of research involved both the application of general scientific methods (scientific documentation, analysis and synthesis of information in the field, the method of theoretical generalization), which made possible the analysis and critical interpretation of data from literature and material, conclusions and recommendations, as well as the methods characteristic of the field of specialization (psychopedagogy, physical culture and sport), including recreational physical culture: analysis of the behavior of the subjects in the fitness trainings and the professional experience of the fitness instructors; pedagogical observation; sociological survey; mathematical-statistical methods of data processing and interpretation; graphical and tabular method.

The fundamental researches of several well-known authors served as a theoreticalscientific and methodological basis, among which M. Epuran [3], A. Dragnea [2], N. Alexe [1], E.P.Ilin [5], A. Maslow [6], M.M. Bulatova, Iu.A.Usaciov [4] et al.

\section{Organization of research}

The research was conducted on a contingent of 40 people, men aged 19-47, who attend gyms and fitness centers in the Chisinau, Republic of Moldova, including: SUPES gym, "Niagara Fitness Club", "ProFitness", "Energy Fitness", "Fitness Doza".

The research was conducted in three stages, presented according to the following description:

In the first stage of the research, theoretical (September - December 2019), the analysis and generalization of data from the literature on issues related to men's motivation for practicing fitness was performed. Based on the analysis of the consulted specialized sources, a sociological survey was elaborated. The contingent of men, who took part in the sociological survey, was also determined at the same stage.

The second stage (October 2019 - March 2020) consisted in the application of the sociological survey to the research topic and in the actual determination of the motivational factors of practicing fitness by the subjects included in the research.

During the third stage (March - April 2020) the processing and calculation of the recorded data were performed, i.e. their processing, as well as the argumentation of the dominant motivational factors of practicing fitness by men. The conclusions and some practical recommendations on stimulating men's motivation for the systematic practice of fitness were formulated. 
Regarding the reasons that determine the men in our country to practice fitness, we consider it appropriate to delimit three main categories: physical condition reasons (desire to have a good health, to prevent various diseases, including the emergence of occupational diseases, the formation of a healthy lifestyle, the strengthening of the functional systems of the body, especially the cardiovascular, musculoskeletal and respiratory, the aspiration to shape a harmonious body, etc); psycho emotional and cognitive reasons (efficiency of intellectual work; improvement of mental state; desire to obtain emotional satisfaction, to feel the joy of movement and physical effort; formation of moral-volitional qualities; tendency to study the theoretical aspects of sports training and technical-tactical training, etc.); socioprofessional reasons (the pleasure of socializing, spending time with friends or making new acquaintances; strengthening the social image, the desire to assert themself in society, to gain a higher social or professional status; the desire to increase their personal prestige in front of people of the opposite sex, the desire to impose authority and respect on those around them, the desire to practice a kind of "fashionable" activity, etc).

The questionnaire included 15 questions, through which we aimed to reveal the following aspects:
- profile of subjects (age, social status, profession, position, etc);

- general aspects of practicing fitness (duration, frequency, type of the practiced sport, training environment, place of fitness in the individual value system);

- the reasons that determine men to practice fitness, according to the three categories: related to physical condition, psycho-emotional and cognitive sphere, socioprofessional sphere, in order to determine the dominant motivational factors, those of increased importance and those of low importance;

- the degree of satisfaction of the subjects following practicing fitness; the role it assigns to the fitness trainer / instructor in obtaining their results.

Later, the recorded data were inserted in a summary table, processed and represented graphically.

In the following, we present the most relevant answers:

We were particularly interested in: the causes / premises of practicing fitness by men, the effects they expect as a result of practicing fitness, as well as the extent to which the subjects managed to achieve their goals and the degree of satisfaction that produced this type of activity (Figures 1-4).
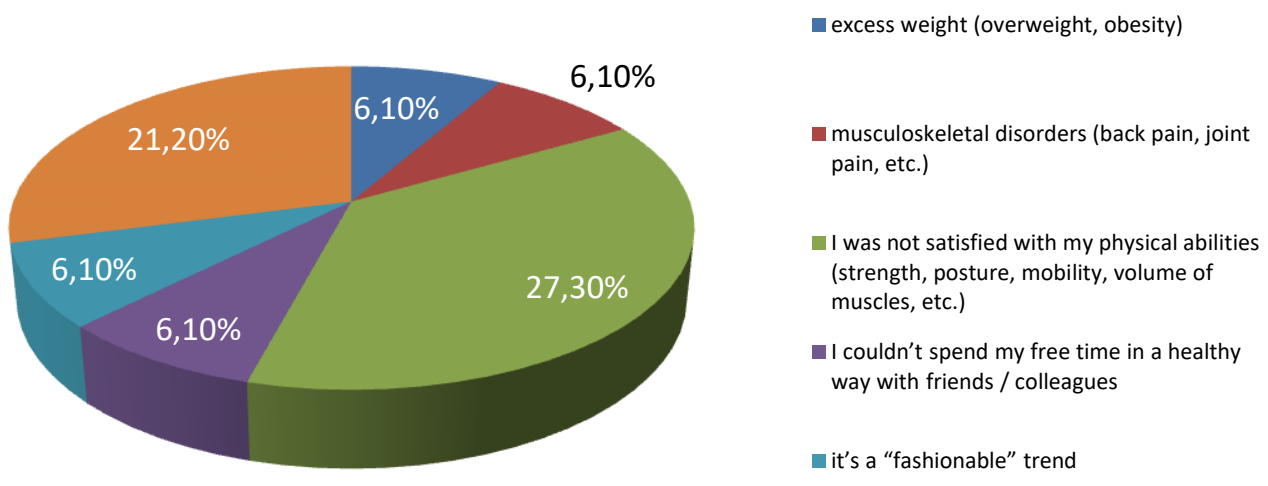

Fig.1. The causes that determined men to practice fitness 
Regarding the causes that guided them to practice fitness (multiple choice question Figure 1), the subjects mentioned, first of all, that they were not satisfied with their physical abilities, on the one hand, and that they always had the pleasure to practice physical exercise, on the other hand - namely these two answers have accumulated the largest number of options - in both cases 18 , which is $27,3 \%$. Another cause is the fact that practicing fitness and, respectively, the benefits that this type of activity has, is a condition imposed by social or professional status - 21,2\% (14 options). The third position is occupied by several options, which were mentioned in equal numbers of respondents: "diseases of the musculoskeletal system (back pain, joint pain, etc.)" - 6,1\%; "Excess weight (overweight, obesity)" - 6,1\%; "I couldn't spend my free time in a healthy way with friends / colleagues" - 6,1\%; "It's a fashion trend" $6,1 \%$. For the other variants of response - the existence of cardiovascular diseases; the state of social isolation, of loneliness; the fact that they had nowhere to consume their energy - he did not choose any subject. It is observed that the main causes that determined men to practice fitness are physical and psychoemotional. This finding could be explained by the observation made by the author Abramov P.N. [16], who believes that caring for one's own body is closely linked to achieving a state of spiritual harmony with the outside world.

To the tenth question, "What purpose/effects do you pursue practicing fitness?" subjects were also able to choose several options (Figure 2).

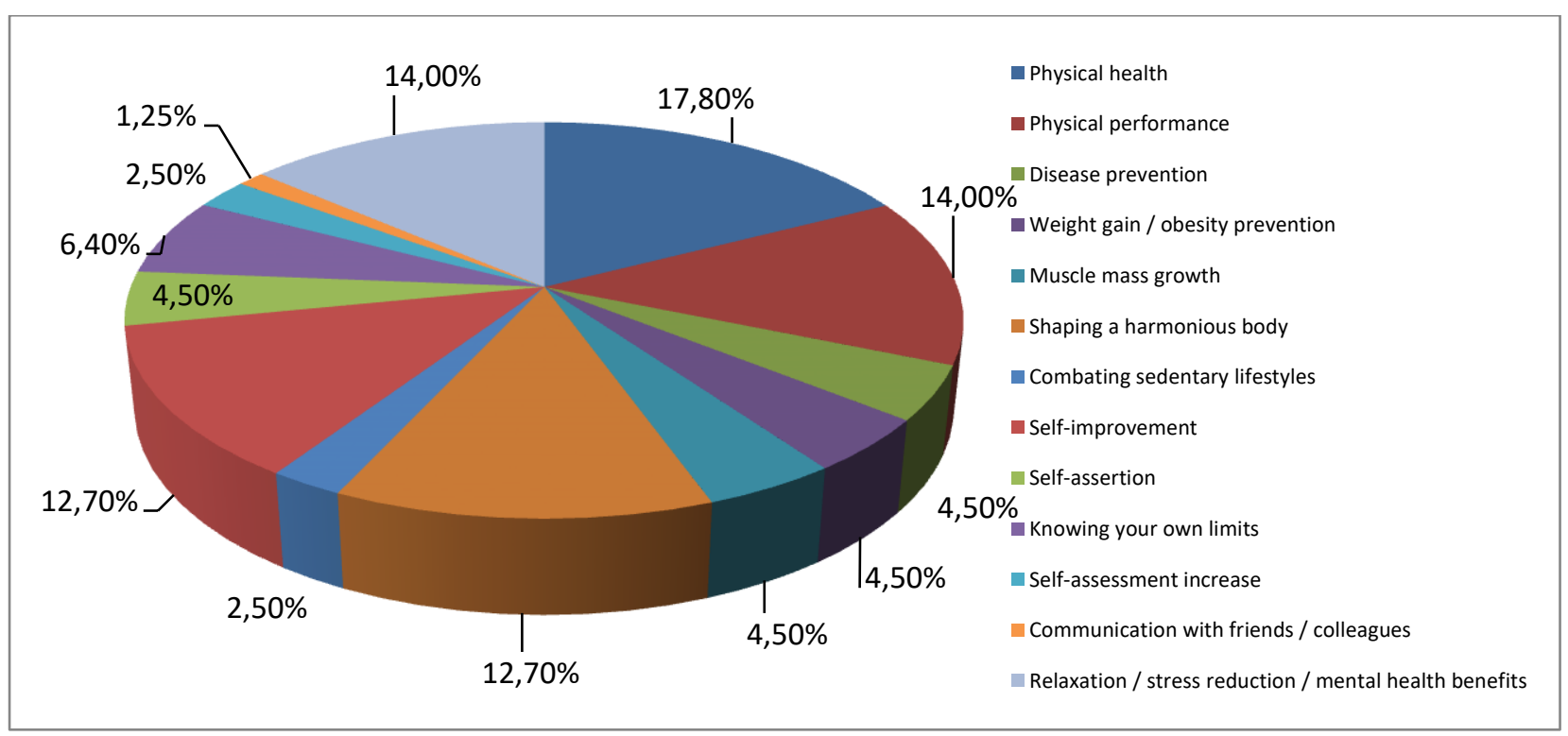

Fig.2. Aims/effects pursued by men through fitness

The analysis of the answers shows that on the first position in the list of benefits that men expect as a result of practicing fitness is the improvement of health, mentioned by 28 respondents $(17,8 \%)$, followed by the options: improving physical performance - 22 (14\%); relaxation/stress reduction / mental health benefits $-22(14 \%)$; and on the third place were the options: shape a harmonious body -
$20(12,7 \%)$, self-improvement - $20(12,7 \%)$. A smaller number of options were given to the response versions: knowing the limits of one's own body - $10(6,4 \%)$; disease prevention (prophylactic purpose) - 7 (4,5\%); weight gain / muscle mass - 7 (4,5\%); self-affirmation - 7 $(4,5 \%)$. A very small number of options accumulated the answers: prevention of weight gain / obesity - 4 (2,5\%); combating sedentary 
lifestyle - $4(2,5 \%)$; increasing the level of self-esteem - $4(2,5 \%)$; communication with friends / colleagues - $2(1,25 \%)$.

It is observed that the main effects that men expect after practicing fitness concern the physical and psycho-emotional sphere (as in the previous case), but the spectrum of expected benefits is greater than that of objective causes, which brought men to Gym. The same aspects are confirmed by the observations, and by the discussions in the interviews conducted by us during the men's fitness training.

At the same time, the aspects related to socialization were not revealed in the answers to these two questions. In this context, we recall another remark made by author
Abramov P.N. [16], which states that, in the process of practicing fitness, interpersonal communication is relatively poorly developed and is maintained mainly on the line "trainer fitness practitioner" or between fitness practitioners outside of training hours. In our survey, we also found that no respondent mentioned as a cause that led him to practice fitness the fact that he felt alone, isolated and no one expects as a benefit the opportunity to meet new people, to connect new friends.

In order to establish the cause-effect relationship, we proposed to the subjects to evaluate the extent to which they managed to achieve their proposed goals (Figure 3 ) and to estimate the degree of satisfaction produced by practicing fitness (Figure 4).

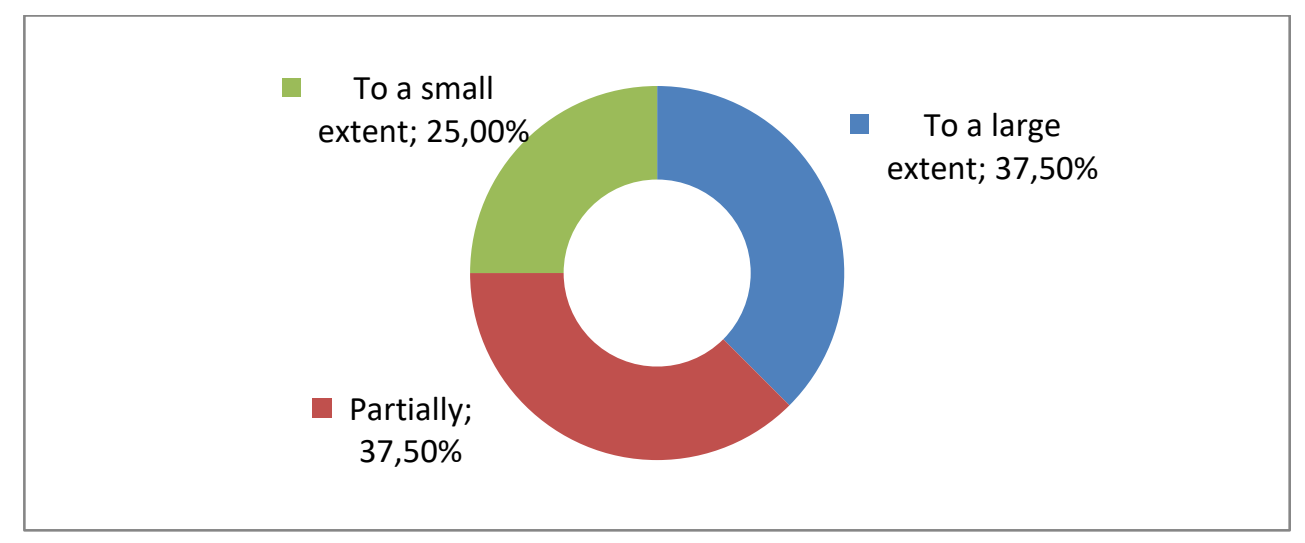

Fig.3. The extent to which fitness practitioners have succeeded in achieving their goals

It is found that a large part of the respondents managed to achieve the effects they expected through practicing fitness and achieved their goals to a large extent $(37,5 \%)$ or partially $(37,5 \%)$. Only 10 subjects answered "to a small extent" (25\%).

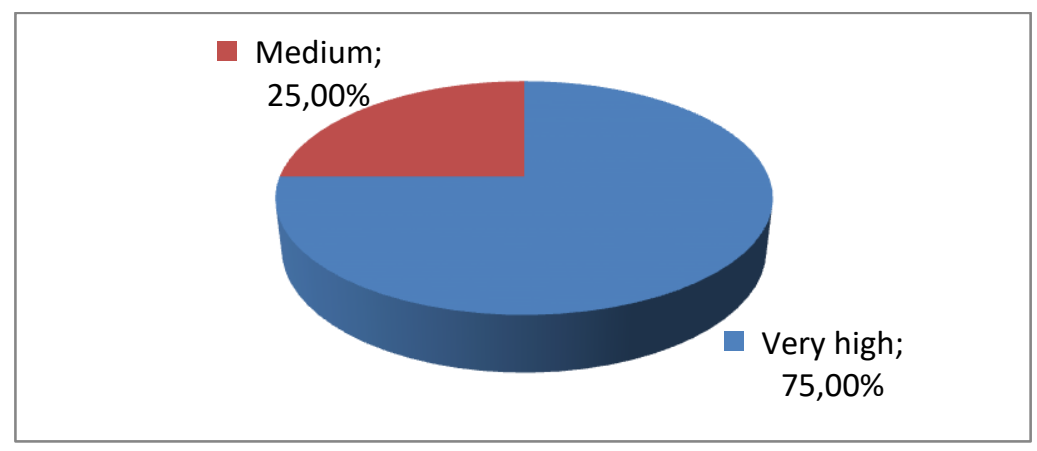

Fig.4. Degree of satisfaction after practicing fitness 
Once the subjects have managed to obtain benefits by practicing fitness activities, their degree of satisfaction is very high (in $75 \%$ of cases) and medium (in $25 \%$ of cases).
By asking the thirteenth question, "What barriers/difficulties did you encounter in achieving your goal?" We wanted to highlight the factors that could to unmotivate the subjects to practice fitness (Figure 5).

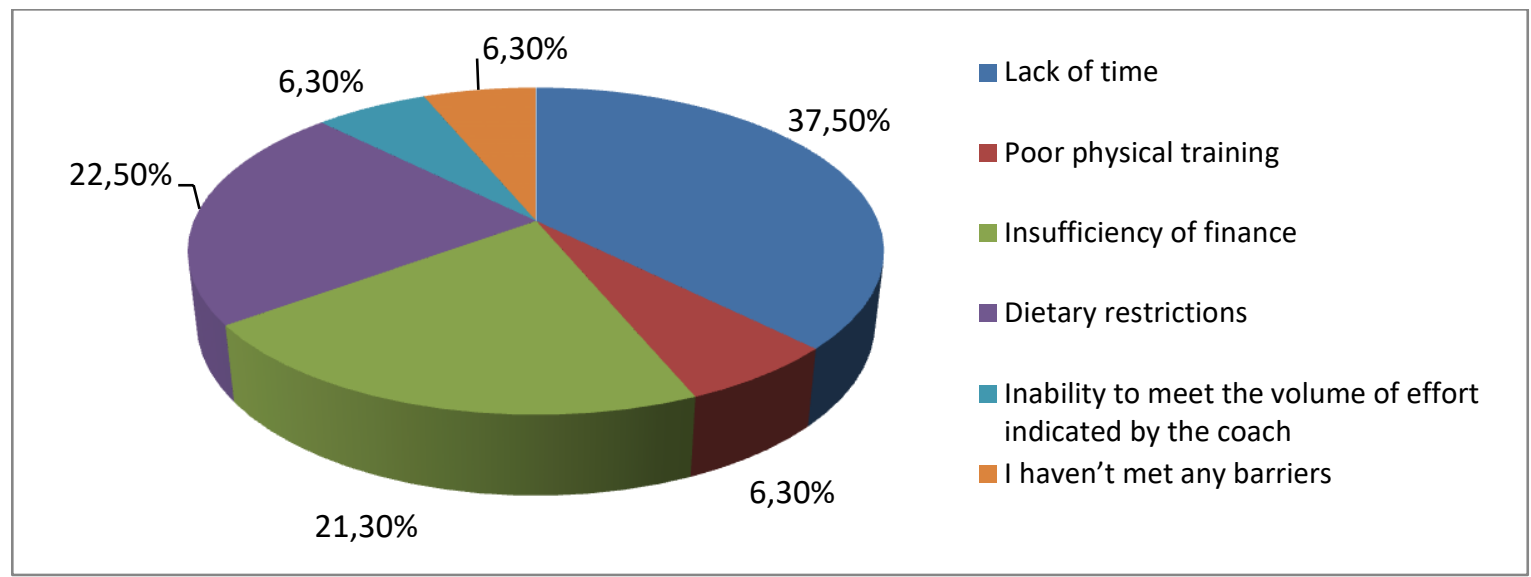

Fig.5. The subjects' answers regarding the barriers / difficulties in conducting the fitness programs

The first observation that is necessary, following the analysis of the answers to this question, is the fact that, although the subjects were proposed 13 variants of answer, their options were concentrated around five answers, which we present in order of importance attributed by these: lack of time - 37,5\%; inability to comply with the imposed diet $22,5 \%$; insufficient finances - 21,3\%; low level of previous physical training $-6,3 \%$ and inability to meet the volume of effort indicated by the coach $-6,3 \%$. Five people $(6,3 \%)$ mentioned that they did not encounter any barriers or difficulties.

The last two questions of the questionnaire referred to the personality of the coach/ fitness instructor, who, in our opinion, is the most important figure both in organizing the training process and in forming the fitness culture of his disciples. Therefore, we considered it necessary to determine whether the subjects are aware of the extent to which the coach's personality influences the results of fitness practice (Figure 6) and what skills he must possess (Figure 7).

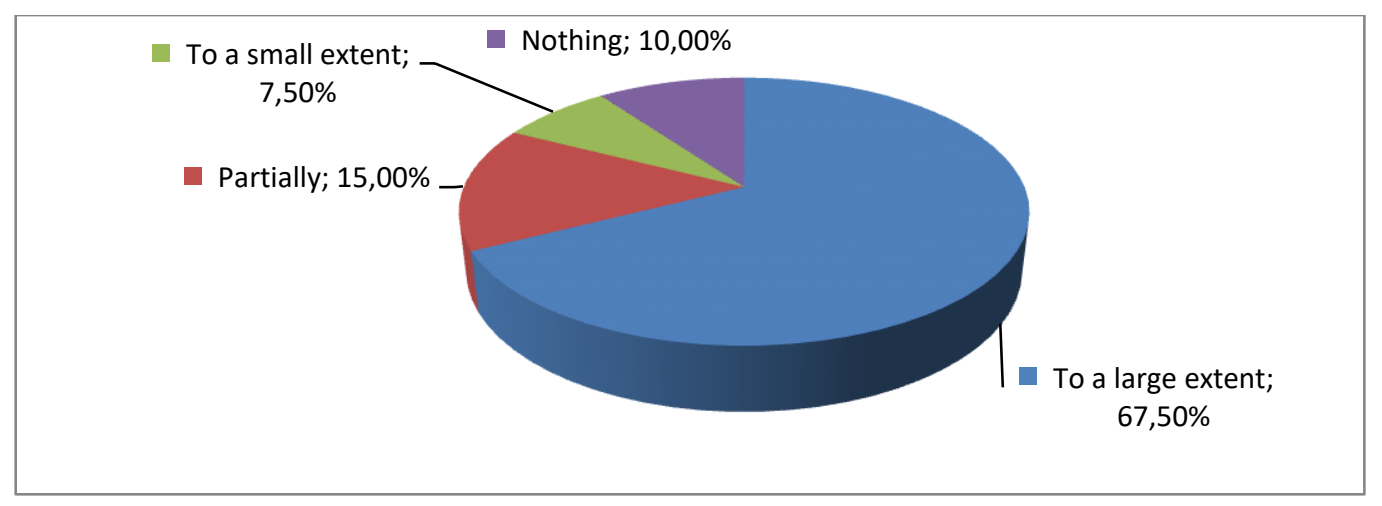

Fig.6. The extent to which the coach's personality influences the results of the subjects 
$67,5 \%$, i.e 27 of the total number of respondents, claimed that the results of fitness practitioners to a large extent depend on the personality of the coach; $15 \%$ (6 people) - that they partially depend; $7,5 \%$ ( 3 people) - that they depend to a small extent; and $10 \%$ (4 people) consider that the personality of the coach does not influence in any way their results.

To the question about the skills needed for a good fitness instructor, the most popular answers were: to know and apply the theory and methodology of physical culture; to be able to compose individualized programs, accessible for each fitness practitioner; to have a good physical condition, i.e to be himself a physical training model - for each of these versions 21 respondents opted (respectively, $8,9 \%$ of the total); three other options were selected by 19 respondents $(8,1 \%)$ : acquire knowledge in the field of sports nutrition; to show respect for those they train; apply the principle of differentiation in fitness training (different programs for different people). On the third position were the competencies related to the psycho-pedagogical training of the instructor: to be a good psychologist; to train the subjects an adequate motivation for practicing fitness; to find the optimal ways to establish contact with fitness practitioners answers mentioned by 17 subjects $(7,2 \%$ for each).

Close values (15 answers each, 6,4\%) were also recorded for the options: to show high moral qualities; to be able to diagnose the evolution of each member of the group; demonstrate communication skills; to be kind, to be able to avoid conflicts. Although the answers to this question are multiple, there is still a tendency to prioritize theoretical skills and physical qualities, then psychopedagogical skills, followed, finally, by the moral qualities of the fitness trainer. The data recorded by us could serve as a starting point for the realization of a professional program of the fitness trainer.

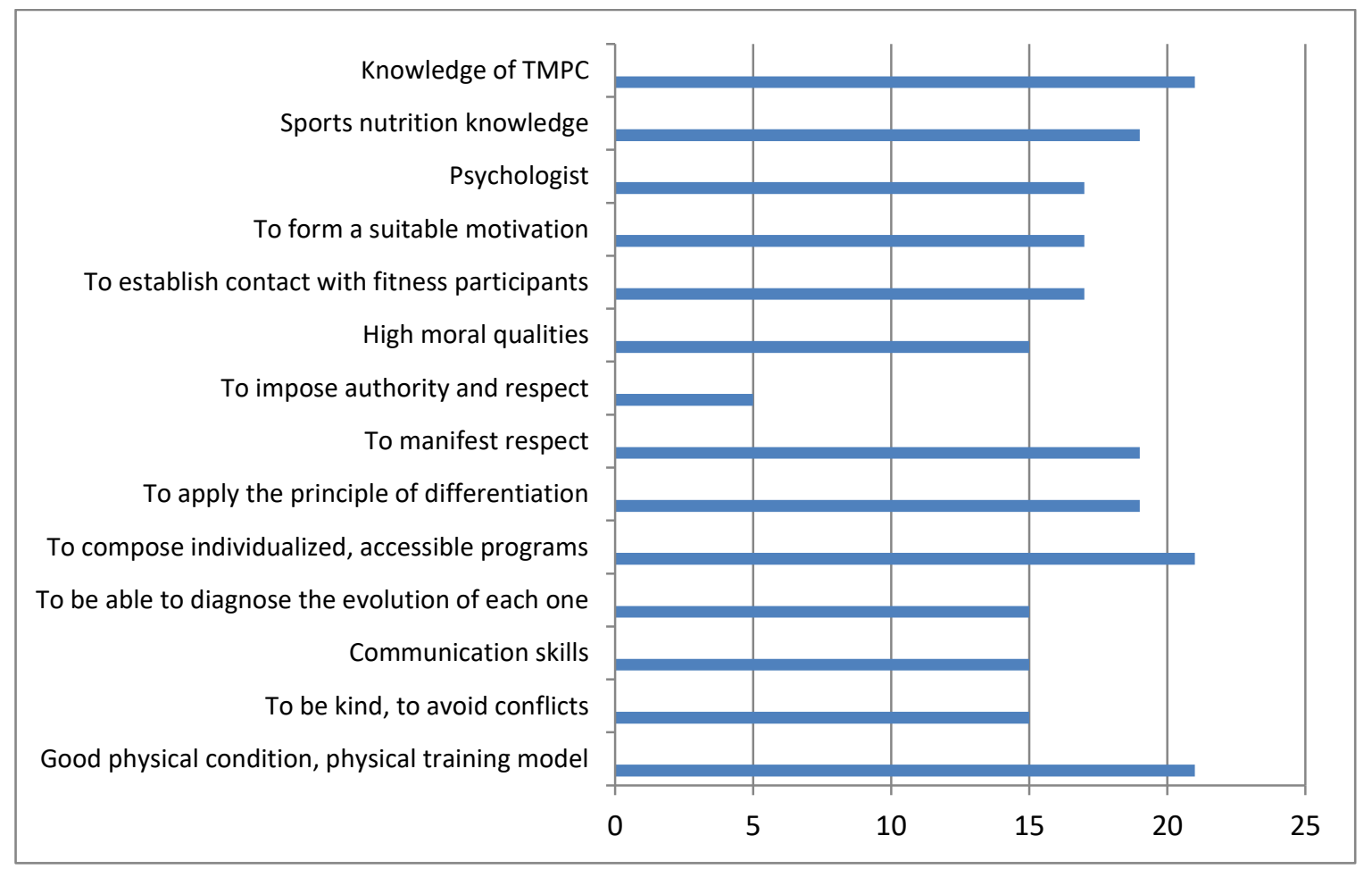

Fig.7. Qualities and competencies required for a fitness instructor 
Summarizing the above, we could mention that the reasons that determine men in the Republic of Moldova to practice fitness are manifested in different ways. The degree of manifestation of the reasons is presented in Table 1.

Table 1. The degree of reasons' manifestation for practicing fitness by men in the Republic of Moldova

\begin{tabular}{|c|c|c|}
\hline No. & $\begin{array}{l}\text { The degree of } \\
\text { reasons' } \\
\text { manifestation }\end{array}$ & Motivational factors \\
\hline 1 & Dominant & $\begin{array}{l}\text { - the desire to be in good health or to improve their physical } \\
\text { health; } \\
\text { - the aspiration to improve their physical performance, the } \\
\text { improvement of motor indices; } \\
\text { - mental health benefits; } \\
\text { - the pleasure to practice physical exercise. }\end{array}$ \\
\hline 2 & Very important & $\begin{array}{l}\text { - } \text { shaping a harmonious body, increasing muscle mass or } \\
\text { reducing body weight; } \\
\text { - disease prevention (prophylactic purpose); } \\
\text { - } \quad \text { the tendency of self-improvement; } \\
-\quad \text { strengthening the social or professional image. }\end{array}$ \\
\hline 3 & Less important & $\begin{array}{l}-\quad \text { combating sedentary lifestyle; } \\
-\quad \text { increasing the level of self-esteem; } \\
\text { - } \quad \text { the desire to practice a "fashionable" activity; } \\
-\quad \text { knowing the limits of its own body; } \\
-\quad \text { communication with friends / colleagues. }\end{array}$ \\
\hline 4 & Unimportant & $\begin{array}{l}\text { - } \quad \text { avoiding loneliness; } \\
\text { - } \text { meeting new people }\end{array}$ \\
\hline
\end{tabular}

Conclusions and recommendations

According to the results of the sociological conducted survey the following essential aspects were determined:

- profile of the subjects: many of the respondents are young, having especially a sedentary lifestyle (students, officials, managers, teachers, businessmen). Most people practice fitness for about 3-12 months, several times a week, but there are also people who practice fitness systematically for over 5 years. Most practice strength tests and usually alternate workouts in gym with those in parks or pools. In the value system of the subjects included in the study, fitness occupies the fourth position, after families, intellectual development and professional training;
- motivational factors of practicing fitness by men, including the causes / premises of fitness and the effects that await them as a result of practicing fitness. The responses of the subjects highlighted the predominance of motivational factors in categories 1 "reasons related to physical condition" (desire to have a good state of health or to improve one's physical health, the aspiration to improve one's physical performance, to improve motor indices, to shape a harmonious body, to increase muscle mass or to reduce one's body weight; to prevent illness) and 2 "reasons of psycho-emotional and cognitive sphere" (benefits for mental health; the pleasure of practicing physical exercise; the tendency to self-improvement; strengthening the social or 
professional image). At the same time, the reasons in the third category "socioprofessional sphere" are either less important (i.e, the desire to practice a "fashionable" activity) or unimportant (i.e, avoiding of loneliness; meeting new people);

- the ratio between the objectives formulated and the recorded results, i.e the extent to which they managed to achieve their objectives and the degree of satisfaction produced by this type of motor activity: a large proportion of respondents managed to achieve the effects they expected through practicing fitness; they have achieved their goals to a large extent $(37,5 \%)$ or partially $(37,5 \%)$, and their degree of satisfaction is very high (in $75 \%$ of cases) and medium (in 25\% of cases);

- the barriers/difficulties encountered by the subjects in achieving the formulated objectives, i.e the factors that could diminish their motivation for practicing fitness: lack of free time for practicing physical exercise $(37,5 \%)$; inability to comply with the imposed diet $(22,5 \%)$; insufficient finances $(21.3 \%)$; low level of previous physical training $(6,3 \%)$ and inability to meet the volume of effort indicated by the coach $(6,3 \%)$.
- the role of the fitness instructor in achieving the training objectives: most of the subjects $(67,5 \%)$ consider that the results of the fitness practitioners largely depend on the personality of the coach, and $15 \%$ stated that they depend partially. At the same time, the respondents consider that the personality of the instructor must be multilaterally developed, priority being given to theoretical skills and physical qualities, then to psycho-pedagogical skills, followed, finally, by the moral qualities of the fitness trainer.

In order to improve the physical condition, the functional, motor and psychomotor aspects of men who practice fitness, an important role belongs to the fitness instructor, who must use his full theoretical, psycho-pedagogical and moral potential in organizing the training process, to develop individualized complex programs, in which to take into account the aspects related to nutrition, effort dosing, the use of recovery means and recuperation of the body, depending on the morpho-functional, mental, etc. of each subject. In this way, the motivation of men to practice fitness will be stimulated.

\section{References:}

1. Alexe N., Constandache V. (2015). Enciclopedia educației fizice şi sportului din România. Ediția a II-a, Vol. VIII. București-Târgu Jiu: Măiastra. 680 p.

2. Dragnea A., Bota A., Teodorescu S., Stănescu M., Șerbănoiu S., Tudor V. (2006). Educație fizică şi sport. Teorie și didactică. Bucureşti: Editura Fest. 300 p.

3. Epuran, M. Psihologie - Compendiu. Bucureşti: MEI ANEFS, 1994.

4. Булатова М.М., Усачев Ю.А. (2003). Современные физкультурно-оздоровительные технологии в физическом воспитании. В: Теория и методика физического воспитания, том 2. Киев: Олимпийская литература, с.342-378.

5. Ильин Е.П. (2011). Мотиващия и мотивы. Серия «Мастера психологии». СанктПетербург: Питер. 512 с.

6. Маслоу А. (2008). Мотиваџия и личность (пер. с англ.), 3-е изд. Серия «Мастера психологии». Санкт-Петербург: Питер. 352 с.

7. Infografic: Cât sport se face în Moldova. [on-line]. http://consulting.md/rom/statistici-sipublicatii/infografic-cat-sport-se-face-in-moldova accesat: 12.11.2019 